\title{
Legrand du Saulle: da agorafobia ao medo dos espaços
}

\author{
Thais Guimarães Rodrigues \\ Mário Eduardo Costa Pereira
}

Henri Legrand du Saulle, célebre alienista francês do século XIX, escreve em 1878 "Estudo clínico do medo dos espaços (a agorafobia dos alemães) - neurose emotiva". Constituindo uma abrangente recapitulação crítica dos trabalhos psiquiátricos do século XIX concernentes à agorafobia, assim como uma ótima compilação de descrições clínicas, esse texto situa os fundamentos dessa psicopatologia, os quais serão posteriormente desenvolvidos tanto pela psiquiatria como pela psicanálise.

Palavras-chave: Agorafobia, medo dos espaços, angústia 
O célebre alienista francês Henri Legrand du Saulle viveu entre 1830 e 1886 . Autor de inúmeras publicações ${ }^{1}$ na área da patologia mental, sua contribuição para o campo psiquiátrico ultrapassa os debates do século XIX, mantendo seu valor para a psicopatologia contemporânea, sobretudo por seus estudos sobre a agorafobia, as obsessões e a problemática psiquiátrica médico-legal.

Legrand du Saulle inicia sua formação médica em Dijon, sua cidade natal. Interessando-se pela psiquiatria, ele parte para Saint-Yon para trabalhar no serviço de Morel. ${ }^{2}$ Seu grande interesse por assuntos legais o faz cursar uma formação em Direito e em 1863 ele é nomeado expert de justiça, passando a ser consultado pelos tribunais e, assim, a realizar avaliações clínicas dos acusados. Mais tarde, em 1867, é convidado a trabalhar no hospício de Bicêtre, a leste de Paris. Apenas um ano depois, já é nomeado médico-assistente de Lasègue ${ }^{3}$ na en-

1. La folie devant les tribunaux (1864), Le délire des persecutions (1871), La Folie héréditaire (1873), Traité de médecine légale et de jurisprudence médicale (1874), La Folie du doute avec le délire du toucher (1875), L'Etude médico-légale sur les épileptiques, entre outros.

2. Sobre Morel, remetemos o leitor a nosso artigo: Pereira, M.E.C., Morel e a questão da degenerescência, Revista Latinoamericana de Psicopatologia Fundamental, São Paulo, v. 11, n. 3, p. 490-496, set.2008.

3. Charles Lasègue (1816-1883), de formação inicialmente literária, descobre a psiquiatria aos 23 anos. Sua obra mais conhecida é Le délire alcoolique n'est plus un délire mais un rêve (1881). Foi, também, o autor da primeira grande descrição do que chamou de "anorexia histérica". Para uma introdução à contribuição de Lasègue, remetemos a nosso artigo: Pereira, M.E.C., Apresentação da anorexia histérica, Revista Latinoamericana de Psicopatologia Fundamental, São Paulo, v. I, n. 3, p. 155-157, set.1998. 
fermaria especial do Dépôt de la Préfecture de Police. Deixa a Bicêtre apenas em 1878 para vir trabalhar na Salpêtrière.

Ao longo do século XIX, a nascente clínica psiquiátrica se desenvolve em grande parte pelo diálogo e pela oposição permanentes de duas grandes escolas, a alemã e a francesa. Apesar da enorme heterogeneidade de pontos de vista, de forma geral, percebe-se nesse momento inicial do pensamento psiquiátrico uma visão prevalente da doença mental como algo de determinação fundamentalmente somática. Contudo, a partir da segunda metade do século XIX observa-se, sobretudo no que concerne aos estudos dos sintomas ansiosos, o advento de uma nova leitura desses fenômenos, em que as possíveis causas psicológicas começam a chamar a atenção.

Durante a década de 1870, vários alienistas isolam uma entidade frequentemente associada às crises ansiosas e emocionais: a agorafobia (cf. Haustgen, 2010). Em 1872, o psiquiatra alemão Karl Frederic Westphal publica "Die Agoraphobie - eine neuropatische Erscheinung", ${ }^{4}$ que consistiria um marco na história da concepção psiquiátrica dos estados fóbicos (Pereira, 2002). Nesse texto, o autor descreve um estado ansioso diretamente relacionado a um temor incontrolável face a um espaço público, o que levaria o agorafóbico a evitá-lo. $\mathrm{O}$ autor desenvolve seu argumento através da preocupação de distinguir a agorafobia de outras patologias, tais como a hipocondria e a epilepsia. Ele considera que o medo constitui seu principal sintoma e não a vertigem, tal como era defendido por Benedict no debate psiquiátrico dessa época.

Seis anos mais tarde, a publicação de sua monografia: "Etude clinique de la peur des espaces (l'agoraphobie des alemands) - névrose émotive"s (1878) relança o debate sobre a agorafobia. A obra inicia, nesse contexto histórico, por uma abrangente recapitulação crítica dos principais trabalhos até então realizados sobre essa patologia. ${ }^{6}$

4. Traduzido em português como: A agorafobia, uma doença neuropática. In: Besset, V.L. (Org.). Angústia. São Paulo: Escuta, 2002. p. 149-171.

5. O termo "neurose" é introduzido pelo escocês Willian Cullen (1710-1790), em 1769, para designar um conjunto de perturbações do sentimento e do movimento que cursam sem febre e sem lesões orgânicas conhecidas. Este termo é empregado por Pinel (1745-1826) em sua classificação das doenças mentais. Cf. Pereira M.E.C., Cullen e a introdução do termo "neurose" na medicina, Revista Latinoamericana de Psicopatologia Fundamental, São Paulo, v. XIII, n. 1, p. 128-134, mar.2010.

6. Legrand du Saulle aponta que esse estado já fora anteriormente descrito por outros autores, tais como Griesinger, Benedikt, Westphal, Cordes, S.Weber, Williams, Brown-Sequard e M.Perroud, sob outras denominações, tais como vertigem dos espaços, agorafobia, angústia dos espaços ou, ainda, receio dos espaços. 
Segundo Legrand du Saulle, a designação "agorafobia”, concebida por Westphal no mesmo texto de 1872 , limita a concepção de tal perturbação psíquica ao medo das praças públicas. Conforme seu próprio entendimento, o medo é efetivamente o sintoma principal dessa patologia, porém ele não deve ser relacionado somente aos espaços públicos. Para ele, o agorafóbico apresenta medo diante de condições espaciais específicas, sobretudo do vazio, o que o leva a nomear esta afecção de "medo dos espaços", abrindo assim uma nova perspectiva para os estudos dessa patologia. Propõe, então, a seguinte definição para essa fobia:

... estado neuropático ${ }^{7}$ muito particular, caracterizado por uma angústia, uma impressão ansiosa viva, ou mesmo um verdadeiro terror, que se produz subitamente em presença de um determinado espaço. Este acidente nervoso é essencialmente emotivo. (p. 5)

Ao longo do trabalho, o autor revela certa dificuldade em sustentar de modo consistente essa definição. Ele se refere à agorafobia de várias formas: estado neuropático, acidente nervoso emotivo, estado ansioso, neurose. Naquele momento da história da psicopatologia, em que se buscava criar uma nosologia e uma classificação sistemáticas para as chamadas doenças mentais, isso não é sem significação. A grande variedade de denominações então propostas à agorafobia reflete a dificuldade para sua delimitação como entidade nosológica específica.

A precisão do conceito de "medo dos espaços" é buscada pela refinada descrição ${ }^{8}$ que o autor faz de seus sintomas em torno de uma problemática específica relativa à espacialidade. Legrand du Saulle ilustra sua narrativa com observações clínicas precisas de casos acompanhados por ele mesmo ou por seus colegas. Tais descrições caracterizam a agorafobia principalmente pela manifestação da angústia, quando o sujeito se encontra em face de uma condição espacial determinada ou a uma situação. Essa estreita relação entre a angústia sentida pelo paciente e a evitação fóbica faz da angústia um ponto capital da agorafobia.

Os sintomas somáticos e psíquicos dos acessos ansiosos observados nessas situações, tais como descritos pelo autor, são correlativos aos chamados "ataques de pânico", conforme descritos atualmente na CID-X e no DSM-IV-R:

7. O termo neuropatia (adjetivo: neuropático) entra no vocabulário médico graças ao artigo "Neuropatia ou vapeurs", de Pougens (1825) para o Dicionário de Medicina Prática. Ele designa assim uma alteração geral do sistema nervoso sem lesão permanente de um órgão particular.

8. A qualidade descritiva de suas observações clínicas, assim como seu esforço de sistematização, testemunham a grande influência exercida em seu método pela psiquiatria de Pinel e Esquirol.

Rev. Latinoam. Psicopat. Fund., São Paulo, v. 14, n. 2, p. 309-317, junho 2011 
De repente, o paciente se torna muito ansioso, tem medo de cair e busca apoio nas paredes das casas ou no braço de alguém. Seu coração bate violentamente, sua pulsação é agitada e um suor abundante se manifesta. Se alguém percebe em que estado ele se encontra ou se ele sabe que está sendo observado nesse momento, sua angústia é ainda mais penosa. Ele teme a cada instante um ataque de apoplexia, mas se mantém de pé durante todo este transtorno emotivo.

Segundo Legrand du Saulle, a onipresença do pânico é uma das principais características do medo dos espaços. O aumento dos batimentos cardíacos, a sudorese, o tremor dos membros inferiores são acompanhados por uma alteração da percepção espacial, por um medo intenso de se sufocar, de enlouquecer, do vazio, de ter medo, de não poder ser assistido por quem quer que seja.

A multiplicidade dos sintomas da agorafobia a torna uma entidade mórbida complexa. Cordes, psiquiatra francês do século XIX, compreende a agorafobia como um dos sintomas de uma neurastenia mais geral, o qual se apresenta sob forma de angústia psíquica de uma série de estados nervosos diferentes (Cullerre, 1888). A visão de Legrand du Saulle se aproxima dessa de Cordes, porém, segundo ele, a agorafobia pode existir de duas formas diferentes: agorafobia idiopática, em que ela constitui uma entidade mórbida por si mesma; e agorafobia secundária, em que ela seria um sintoma secundário de uma entidade mórbida principal.

Ao questionar-se sobre a etiologia da agorafobia idiopática, o autor não é conclusivo. No entanto, a agorafobia secundária é considerada como um aspecto de uma neurose mais geral, não sendo um acidente isolado na existência do agorafóbico. Ele enfatiza a importância da hereditariedade e admite, assim como Cordes, a influência que pode exercer uma dada conjuntura atual da vida do doente, tais como "trabalho intelectual exagerado, uma vida desregrada ou com perdas seminais e perturbações dispépticas", sobre a etiologia dessa afecção.

Ainda na tentativa de melhor circunscrever a etiologia da agorafobia, Legrand du Saulle investiga a historicidade dessa patologia. Os casos clínicos são construídos pela descrição dos sintomas apresentados pelo doente ao longo do tempo. Quando os sintomas começaram a aparecer? Os sintomas apresentavam a mesma forma desde sua primeira aparição? Como, por exemplo, no caso trazido na observação 1:

Faz 15 anos que, logo depois de uma viagem para a Suíça durante a qual subiu ao Righi, ela não consegue atravessar os Champs-Elysées, as avenidas, uma grande praça ou uma rua larga, sem no mesmo instante ser tomada por uma penosa angústia, por um medo estranho e ter seu corpo parcialmente ou inteiramente trêmulo. (p. 9)

Ele trata a agorafobia a partir de seu caráter evolutivo. Nessa perspectiva, ela é analisada como produção histórica, ou seja, em seu desenvolvimento tem- 
poral. Aqui vale destacar que, na história da psiquiatria, esta visão longitudinal da psicopatologia foi longamente trabalhada por Falret, ${ }^{9}$ psiquiatra francês de grande importância, contemporâneo de Legrand du Saulle, cuja contribuição é fundamental para a construção do saber psiquiátrico.

Outro aspecto de destaque em seu texto de 1878 se refere à preocupação do autor em definir a agorafobia como "uma situação patológica real, penosa e digna de respeito" (p. 63), enfatizando que o agorafóbico não perde a razão, distinguindo-a de outras afecções. A agorafobia é uma neurose emotiva da qual o doente tem plena consciência, mas perante a qual ele é impotente (Cullerre, 1888). Legrand du Saulle sugere então que seu tratamento deve repousar sobre uma relação de confiança entre o médico e o paciente, de maneira a possibilitar que este confesse a seu médico todas as suas angústias e ideias relacionadas. Ao médico, por sua vez, caberia destruir com sua autoridade cada uma de suas apreensões.

No fim do século XIX, aparecem os primeiros trabalhos da psicanálise sobre a agorafobia. Partindo de ideias herdadas da psiquiatria, Freud desenvolve duas perspectivas dessa psicopatologia que diferem entre si, sobretudo em relação a sua etiologia, e relacionam-se aos conceitos de neurose atual e neurose de defesa. Em seus estudos sobre as neuroses atuais, ele concebe a agorafobia como uma reação secundária aos ataques de angústia. Já em relação às neuroses de defesa, sobretudo à histeria, os sintomas agorafóbicos revelariam um conflito de natureza sexual (cf. Pereira, 1999).

A contribuição de Legrand du Saulle sobre o "medo dos espaços" esboça, pois, algumas das questões centrais que fundam os pilares teóricos para a compreensão dessa psicopatologia e que serão posteriormente desenvolvidas, tanto pela psiquiatria como pela psicanálise.

"Étude clinique de la peur des espaces" permite a constituição de um olhar psicopatológico dirigido a tais condições fóbicas capaz de interrogar a posição do sujeito - para além da situação espacial concreta em que se encontra - em sua relação com o espaço enquanto tal, em relação à amplidão, ao vazio, ao possível e ao desamparo do ser face à abertura radical na qual se desenrola sua existência. Nas palavras do próprio Legrand du Saulle:

O doente, agora tomado por uma emoção indefinível, se encontra isolado do mundo inteiro, frente ao vazio que se oferece a ele e que é vivido como algo sem medidas. (...) Pálido, ele se arrepia, cora, cobre-se de suor, alarma-se cada vez mais, mal consegue se sustentar sobre suas pernas e fica dolorosamente conven-

9. Sobre Jean-Pierre Falret, remetemos o leitor a: Ramos, F. A. da C., Jean-Pierre Falret e a definição do método clínico em psiquiatria, Revista Latinoamericana de Psicopatologia Fundamental, São Paulo, v. XIII, n. 2, p. 296-306, jun.2010. 
cido de que ele nunca poderá se confrontar com esse vazio, esse lugar deserto, e atravessar o espaço que a ele se apresenta.

\section{Referências}

BERCHERIE, P. (1991). Histoire et structure du savoir psychiatrique, tome 1: les fondements de la clinique. Paris: L'Harmattan, 2004.

. Clinique psychiatrique, clinique psychanalytique: Etudes et recherches 1980-2004. Paris: L'Harmattan, 2005.

Cullerre, A. La peur des espaces. In: Les frontières de la folie. Paris: Éd. J.-B. Baillière et fils, 1888.

Freud, S. (1895). Du bien-fondé à séparer de la neurasthénie un complexe de symptoms déterminé, en tant que "névrose d'angoisse". In: Oeuvres Complètes de Psychanalyse. Paris: PUF, 1989. t. III, p. 29-58.

. (1898). La sexualité dans l'étiologie des névroses. In: Oeuvres Complètes de Psychanalyse. Paris: PUF, 1989. t. III, p. 215-240.

Haustgen, T. (2010). Les états anxieux dans l'histoire de la médecine Première partie: d'Hippocrate au "nervosisme". PSN. doi:10.1007/s11836-010-0147-6.

Legrand du SAULle, H. Études cliniques de la peur des espaces (L'agoraphobie des allemands) - néurose emotive. Paris: Libraires-éditeurs, 1878.

Morel, P. (1995). Dictionnaire biographique de la psychiatrie ([Nouv. éd.].) Empecheurs Penser en Rond, Plessis-Robinson, 1996.

Pereira, M.E.C. Westphal e a descrição da agorafobia. In: Besset, V.L. (Org.). Angústia. São Paulo: Escuta, 2002. p. 141-147.

. Pânico e desamparo. São Paulo: Escuta, 1999.

WestPhal, K. (1872). A agorafobia, uma doença neuropática. In: Besset, V.L. (Org.). Angústia. São Paulo: Escuta, 2002. p. 149-171.

\section{Resumos}

(Legrand Du Saulle: from agoraphobia to fear of open spaces)

In 1878 Henri Legrand du Saulle, a famous $19^{\text {th }}$-century French psychiatrist, wrote "Clinical study of the fear of spaces (the Germans' agoraphobia) - emotional neurosis." This text is a comprehensive critical summary of all work on existing psychiatric 
agoraphobia at the time, and an excellent compilation of clinical studies. Above all it offers us the foundations for psychopathology, which was further developed by psychiatrists and psychoanalysts.

Key words: Agoraphobia, fear of spaces, anxiety

(Legrand du Saulle: de l'agoraphobie à la peur des espaces)

Henri Legrand du Saulle, célèbre aliéniste français du XIX siècle, rédige en 1878 l"Étude clinique sur la peur des espaces (l'agoraphobie des Allemands) - névrose émotive". Ce texte constitue une vaste récapitulation critique de tous les travaux psychiatriques existants sur l'agoraphobie à cette époque, ainsi qu'une excellente compilation d'études cliniques. Elle nous révèle surtout les fondements de cette psychopathologie qui seront par la suite développés par la psychiatrie et la psychanalyse.

Mots clés: Agoraphobie, peur des espaces, angoisse

(Legrand Du Saulle: de la agorafobia al miedo a los espacios)

Henri Legrand du Saulle, un célebre psiquiatra francés del siglo XIX, escribió en 1878 "Estudio clínico del miedo a los espacios (la agorafobia de los alemanes) neurosis emotiva”. Una amplia recapitulación crítica de los trabajos psiquiátricos del siglo XIX sobre la agorafobia y una excelente compilación de descripciones clínicas. Ese texto lanza los fundamentos de esa psicopatologia específica, los cuales fueron desarrollados ulteriormente por la psiquiatria y por el psicoanálisis.

Palabras clave: Agorafobia, miedo a los espacios, angústia

Citação/Citation: Rodrigues, T.G.; PereiRA, M.E.C. Legrand du Saulle: da agorafobia ao medo dos espaços. Revista Latinoamericana de Psicopatologia Fundamental, São Paulo, v. 14, n. 2, p. 309-317, jun.2011.

Editor do artigo/Editor: Prof. Dr. Mario Eduardo Costa Pereira

Recebido/Received: 6.2.2011 / 2.6.2011 Aceito/Accepted: 15.4.2011 / 4.15.2011

Copyright: (C) 2009 Associação Universitária de Pesquisa em Psicopatologia Fundamental/ University Association for Research in Fundamental Psychopathology. Este é um artigo de livre acesso, que permite uso irrestrito, distribuição e reprodução em qualquer meio, desde que o autor e a fonte sejam citados/This is an open-access article, which permits unrestricted use, distribution, and reproduction in any medium, provided the original author and source are credited.

Rev. Latinoam. Psicopat. Fund., São Paulo, v. 14, n. 2, p. 309-317, junho 2011 
Financiamento/Funding: Os autores declaram não ter sido financiados ou apoiados/The authors have no support or funding to report.

Conflito de interesses/Conflict of interest: Os autores declaram que não há conflito de interesses/The authors declare that has no conflict of interest.

\section{Thais Guimarães Rodrigues}

Psicóloga graduada pela Universidade de São Paulo - USP (São Paulo, SP, Brasil); Mestranda em psicologia clínica pelo Laboratoire de Psychopathologie Clinique et Psychanalyse da Universidade de Provence/Aix-Marseille (Marseille, França).

72, Bd Notre Dame

13006 Marseille France

e-mail: thaisgr@yahoo.com

\section{Mario Eduardo Costa Pereira}

Psiquiatra; psicanalista; Diretor científico e professor titular de Psicopatologia Clínica do Laboratoire de Psychopathologie Clinique et Psychanalyse da Universidade de Provence/ Aix-Marseille (Marseille, França); Doutor em Psicopatologia Fundamental e Psicanálise pela Universidade de Paris 7 (Paris, França); Membro da Associação Universitária de Pesquisa em Psicopatologia Fundamental (São Paulo, SP, Brasil); Autor dos livros Pânico e desamparo (São Paulo: Escuta, 1999) e Psicopatologia dos ataques de pânico (São Paulo: Escuta, 2003); Membro do departamento de Psicanálise do Instituto Sedes Sapientiae (São Paulo, SP, Brasil)

Laboratoire de Psychanalyse et Psychopathologie Clinique

Université de Provence

Centre Saint-Charles

Case 37

3, place Victor Hugo

13331 Marseille cedex 3 France

e-mail: mario-eduardo.costa-pereira@univ-provence.fr 